\title{
Noção de Meio Ambiente no Direito Brasileiro
}

\author{
Bernadete Ferreira Farias*
}

\begin{abstract}
Sumário: Introdução; 1. Primeiras idéias; 2. Significado do termo ambiente; 3 . O termo ambiente no direito brasileiro; 4 . O conceito do termo ambiente; 5. Conclusão
\end{abstract}

\section{Introdução}

A nossa atenção focaliza o objeto central do estudo do Direito Ambiental: o ambiente. A discussão central que se tem desenvolvido no seio da comunidade jurídica internacional é a de que uma compreensão indeterminada do ambiente, como o objeto do Direito, somente traria um caráter meramente indicativo, programático e imperialista à sua concepção jurídica. O conceito de ambiente, definido dentro de critérios claros, é a meta sob o ângulo do direito ambiental comparado. Motivada por essas discussões doutrinárias, caber-nos-á também realizar uma aproximação prospectiva do objeto de estudo no direito ambiental-pátrio, o que nos conduzirá a revelar qual a concepção jurídica dada pelo legislador brasileiro ao termo ambiente. Este, no Direito comparado, tem diferentes definições, por vezes omitidas e porta domínios técnico-jurídicos de proteção amplo ou restrito ao seu conteúdo, como veremos.

Como referências bibliográficas de fundo ao desenvolvimento do presente estudo, consultamos Rámon Martin Mateo, e outras fontes creditícias do Direito comparado: Jean Lamarque: Michel Despax, entre outros.

* Pesquisadora Recém-Dout ora pelo CNPq/Brasília junto ao CPGD/UFPR; Professora no Curso de Doutor em Meio Ambiente e Desenvolvimento PRPPG/UFPR: Membro do Núcleo de Estudos Jurídicos do CPGD/UFPR: Doutora em Direito Ambiental pela Université de Strasbourg III - França.

R. Fac. Direito. Curitiba. a.27. n.27. 1992/93, p.81-91 


\section{Primeiras idéias}

As primeiras idéias concebidas do ambiente estão ligadas aos movimentos ecológicos, que tiveram início no século XVIII, com as manifestações intelectuais românicas de Rousseau. Este, preconizava a volta à natureza para fazer defesa frente aos primeiros avanços da civilização industrial. A partir daí, desenvolveram-se no mundo inteiro correntes de diferentes ângulos de cunho ético (fomento do excursionismo, criação de festas, etc) e científico: movimento conservacionista, como o de Charles Darwin, que animou a criação de sociedades científicas do tipo da Sociedade Ecológica Londrenense (1830), da Sociedade Inglesa para a Proteção de Aves (1889) e da Sociedade de Ecologia Inglesa (1913), para citar algumas, entre as mais pioneiras.

Até as últimas décadas do século XIX, os esforços eram direcionados para a criação de categorias jurídicas de proteção da natureza, cuja finalidade principal era a de manter intactas determinadas partes do território, especialmente qualificadas por sua beleza ou por sua riqueza de espécie e formas de vida sui generis. A criação do Parque Yosemite em 1865 e a do Parque Nacional de Yellowstone em 1872, movimentos que receberam incostestavelmente o apoio do presidente Teodoro Roosevelt, são ilustrações pioneiras de medidas federais. No tempo, tais medidas governamentais conservacionistas adquirem notável impulso, estimulando adiante iniciativas similares em outros países.

\section{Significado do termo ambiente}

A palavra ambiente deriva do verbo latim ambio, is, ivi itum, ire, que significa rodar, cercar por todas as partes. ${ }^{1} \mathrm{O}$ ambiente é definido como "o conjunto de condições naturais e de influências que atuam sobre os organismos vivos e os seres humanos". ${ }^{2}$ No tempo, seu significado é tomado em diferentes sentidos: dentro de uma perspectiva globalista inclui toda problemática ecológica geral, e também a utilização dos recursos, à dis-

1 José Cretella Junior e Geraldo de Uchôa Cintra, Dicionário Latino-Português, São Paulo, Companhia Editora Nacional, 1953, p. 76.

2 Novo Dicionário Aurélio da Lingua Portuguesa, Rio de Janeiro, J.E.M.M. Editores Ltda., p. 1113. 
posição do homem na biosfera, consagradas nas declarações de princípios. Convém lembrar a mais célebre, firmada em Estocolmo em 1972, da qual provém o direito fundamental do homem a um meio de qualidade, encobrindo, ainda, a idéia de patrimônio como coisa comum a todos os homens: "O homem tem o direito fundamental à liberdade e ao desfrute de condições de vida adequadas em um meio de qualidade tal que lhe permita levar uma vida digna e gozar de bem-estar, e tem a solene obrigação de proteger e melhorar o meio para as gerações presentes e futuras". ${ }^{3}$

No entanto, no entender de Ramón Martin Mateo, tais documentos mais representam princípios orientadores de politica do Direito, do que de postulados de transcendência juridica imediata. De fato, o conteúdo técnico jurídico do Direito Ambiental não pode estruturar-se sobre tais bases e exige, por isso, uma formulação de objetivos concretos à instrumentação de um determinado sistema normativo. ${ }^{4}$

Seguindo estas manifestações de princípios fundamentais, o direito ao meio ambiente ecologicamente equilibrado encontra acolhida em numerosas constituições estrangeiras: Constituição soviética de 1977 (art. 18), chinesa de 1978 (art. 11), portuguesa de 1976 (art. 66). O seu reconhecimento é também consagrado em legislações ordinárias de paișes que se mantinham até então tímidos às orientações políticas de Estocolmo, como a lei francesa de 10 de julho de 1976, relativa à proteção da natureza: em início dos anos oitenta, o termo é definido na lei brasileira de 31 de agosto de 1981.

\section{O termo ambiente no direito brasileiro}

Não fugindo ao hábito comum influenciado pela literatura jurídica estrangeira, ${ }^{5}$ o termo ambiente no Direito Pátrio apresenta conteúdo incerto

3 Fernando Bodelon Fuentes. (Calidade de Vida, Medio Ambiente y Ordenacion Del io textos internacionais. Madrid. CEOTMA/CIFCA. 1982. p. 49.

4 Ramón Martin Mateo. Tratado de Derecho Ambiental. v. I. Madrid. Ed. Trivium. 1991

5 João Ferreira Reis. Contributos para uma Teoria do Direito do Ambiente. Jisboa. Secretaria do Estado do Ambiente e dos Recursos Naturais. 1987. p. 69: “uma consulta a legislação de diversos países. chegar-se-á a uma de duas conclusões: ou o conceito de meio ambiente é pura e simplesmente omitido. ou das definiçóes possuem as características e elementos mais diversos. E se não existisse unanimidade yuanto a definição de Ambiente tal qual lacuna demonstrariao espírito criativo do bomem no

R. Fac. Direito. Curitiba. a.27. n.27. 1992/93, p.81-91 
e de contorno indeterminado, cabendo citar as observações de Martine Rémond Gouilloud, ${ }^{6}$ formuladas lato sensu, com base no conceito de ecologia, ligado às Ciências Naturais. O legislador o define no artigo $3^{\circ} \mathrm{da}$ Lei $\mathrm{n}^{\mathrm{O}} 6.938 / 81$, que dispõe sobre a Política do Meio Ambiente: "art. $3^{\circ}$

processo de formação das leis. Para a primeira conclusão, a Lei de base da Venezuela de 15 de junho de 1976, o código dos recursos naturais da Colômbia, de 23 de dezembro de 1974 e a Lei Romena de 20 de julho de 1973. Para a segunda conclusão, a Lei Geral sobre a proteção da República Popular da China de 13 de setembro de 1979 define ambiente como "atmosfera, água, o solo, recursos minerais, florestas, as zonas verdes, a vida selvagem, as plantas selvagens, as plantas aquáticas, a fauna piscícula, lugares de interesse ou históricos, paisagens, mananciais termais, instalações para saúde, espaços naturais protegidos, zonas residenciais". No Canadá a Lei sobre qualidade do ambiente definiu este como: "a água, a atmosfera, o solo ou a combinação de um ou de outro, ou de modo geral meio com o qual as espécies mantém relações dinâmicas". Lei n ${ }^{\circ} 6.938 / 81$ do Brasil, sobre Política Nacional do Ambiente estabelece que se entende por meio ambiente "o conjunto de condições, leis, influências e interações de ordem física, química e biológica que permite, abriga e rege a vida em todas as suas formas". Lei sobre Proteção do Ambiente do México, publicada em 11 de janeiro de 1982 define ambiente como conjunto de elementos naturais, artificiais ou induzidos pelo homem, físicos. químicos que propiciam a existência, transformação e desenvolvimento dos organismos vivos. Em Cuba a Lei ${ }^{\circ} 33$ de 10 de janeiro de 1981 define meio ambiente como o "sistema de alimentos (ou subsistemas) abiótipos, biótipos e socioeconômicos com o qual interactua para satisfazer as suas necessidades".

6 Martie Rémond Gouilloud. Du Droit de Detruire, Paris, Puf, 1989, p. 43: "Le mot existe mais il ne correspond pas à un concept précis. L'idée est claire dans son noyaou central et parfaitement imprécise dans ses contours (Lanversin). Et l'on hésite sur son contenu: Que retenir comme constituant de l'environnement? Le dictionaire Larousse définit l'environnemet comme l'ensemble des élémentes naturales ou artificiels qui conditionment la vie de l'homme. Chacun de ces termes doit être pesé: 1) conditionnent: parmi les élémentes qui nous entourent qui nous environnent au sens traditionneel du terme, seuls être pris en considerátion ceux qui ont une influence: 2) parmi eux nous ne retiendrons que les éléments naturales. dons de Dieu reçus par l'homme en héritage: le donné. par oposition au construit, la natura naturante dont parle Spinoza. L'environnement artificiel, bâtiments oeuvres d'art autres rélisations humaines inspirent une reflexion different de celle qui s'attache au milieu naturel: que l'homme décide de détruire son passé est une question grave, mais ce n'est pas la nôtre ici: 3 ) ces elements influencent notre vie. De quelle manière? C'est affaire de bien-être si l'effluve maladorante nous cause une gêne, mais si elle nous asphyxie, c'est affaire de survie. L'envirounement interésse donc la santé physique et psychologique (Lamarque, p. XV). Faut-il pour autant ramener l'environ ement à une seule question de santé? Les deux préocupations sont certs proches. De droit communautaire n' a jamais fait clairament la distinction ... L'Acte Unique européen en témoigne en inscrivant la protection de la santé parmi les objectifs de l'action de la Commumauté en mantière d'environnement (Art. 130 R.1). Cette aproche paraite portant singulièrement réductrice. Complémentaires les deux disciplines poursuivent parfois des objectives contradictoire". 
Para os fins previstos nesta Lei, entende-se por: I Meio Ambiente: o conjunto de condições, leis, influências e interações de ordem física, química e biológica, que permite, obriga e rege a vida em todas as suas formas". 7

Significado similar foi dado pelo Conselho Internacional da língua francesa, para o qual é: "L’ensemble, à un moment donné, des agents physiques, chimiques, biologiques et des facteurs sociaux susceptibles d'avoir un effet direct ou indirect, inmédiat ou à terme, sur les êtres vivants et les activités humaines". 8

A falta de clareza terminológica dada ao significado jurídico é questionada por Jean Lamarque que chega à conclusão de que, dentro de uma perspectiva técnico-conceitual, tudo pode estar incluindo no termo: "Aussi bien l'enseignement, les loisirs, les sports, le problème des transports, la diffusion de la pensèe, les arts, la médicine, le régime hospitalier, la criminologie, la grastronomie et, bien entendu, la sexualité...".?

Mas, se, para definir ambiente, o legislador brasileiro não prescinde da idéia de ecologia, historicamente a mais primária, qual, então, o conteúdo jurídico dado ao conceito de meio ambiente que provém da Constituição Federal de 1988? Meio ambienté é expressão que compreende a natureza?

\section{Conceito do termo ambiente}

O termo ambiente não é sinônimo de natureza e seu conteúdo é objeto de discussão: João Pereira Reis, discorda, em parte, de Jean Untermaoab, da exclusão feita por este doutrinador francês, dos problemas relativos

\footnotetext{
Legislação básico. Ministério do Interior SEMA. Brasilia. 1983. p. 104-111.

$s$ Jean Iamarque. Droit de la protection de la nature et de l'environnement. Paris. L.G.D.J.. 1973. p. XIV. af irma ainda que: "Il existe, pensons nous, un double lien entre 1'Environnement et la Nature. La protection de l'Environnement se trove en cause lorsqu un élément natural. tel l'eau ou l'air. devient le véhicule de nuisances susceptibles de compromettre l'équilibre psychophisiologique de l'homme. Plus que le mieux-ètre. la lutte contre la pollutions atmosphérique a ainsi pour object if fondamental la protection de la santé publique. Par ailleurs. assurer la protection qualit ative de la ressource en eau. combattre les pollutions atmosphériques. cest encore protéger la nature. c'est la conserver dans sa pureté."

9. Jean Lamarque. Droit... op. cit.. p. XIV.
}

R. Fac. Iircito. Curitiba, a.27. n.27. 1992/93. p.81-91 
à conservação das espécies do conteúdo da natureza. Fundamenta sua visão sobre dois grandes grupos de fatores ou elementos que compõem o ambiente: o elemento natural (a fauna e a flora selvagens, bem como a água, o ar ou o solo) e o elemento construído (os que resultam da atividade humana). Segundo aquele doutrinador português, diferenciar ambiente de naturezade forma alguma significa aceitar que certas questões relativas à proteção da natureza não interessam ao ambiente: "Seja qual for a definição perfilhada, terá uma vocação mais ampla do que o conceito de natureza, na medida em que tende a abarcar a totalidade do quadro de vida do homem, no qual se incluem os fatores criados ou construídos pelo próprio homem, e não apenas os elementos naturais que o homem veio encontrar à face da Terra". ${ }^{10}$

No mesmo sentido, Jean Lamarque, para o qual a proteção do ambiente e da natureza pertencem a domínios distintos. Suas considerações teoricamente vêm expressas no título do livro Droit de la Nature et de l'Environnement: "O primeiro domínio compreende a proteção dos conjuntos (sítios e monumentos culturais, parques nacionais e naturais) e a proteção dos elementos da natureza (o ar, a água, o solo, os bosques, flora e fauna); o segundo domínio, ao lado das regras e das técnicas de proteção, concerne à proteção dos estabelecimentos licenciados, à preservação das águas e da atmosfera e à luta contra o barulho". ${ }^{11}$

Contrário às teses, predominantes no Direito comparado, de conceber o objeto central do Direito Ambiental como uma aplicação ampla no espaço, ${ }^{12}$ Ramón Martin Mateo tem uma visão doutrinária ainda mais restrita do ambiente, que, além de descartar de seu domínio conceitual a noção de território global (que é objeto da ordenação do território) e somente admitir uma identificação parcial com a natureza, ${ }^{13}$ somente inclui

10 João Ferreira Reis, Contributos ..., op. cit, p. 18: "A este propósito sublinha J. Untermaier "que ambiente e natureza não são exatamente sinônimos. O primeiro amplia e reduz em simultâneo o conceito de natureza. Engloba elementos que the são estranhos, em particular o espaço urbano. ao inverso, a natureza coloca problemas que não interessam ao ambiente em sentido estrito nomeadamente os relativos à conservação das espécies '".

11 Jean Lamarque, Droit... op. cit.. p. XIV.

12 Um exemplo extremo de compreensão globalista do ambiente: a lei francesa de Proteção da Natureza inserindo ítens como a ação contra a contaminação, o meio urbano, as paisagens rurais, etc.

13 Ramón Martin Mateo, Tratado de Derecho Ambiental. Vol. I. Madrid, 1991, p. 84. "Pero aunque el ambiente sea una parte de la natureleza en su conjunto se desabrega en múltimples estrategias sectoriales: proteccíón de la caza, de los bosques, de los parques naturales, de los recursos naturales e incluso ampliando el concepto ilega a incluir los 
no seu conteúdo: "aqueles elementos naturais de titularidade comum e de características dinâmicas: em definitivo, a água, e o ar, veículos básicos de transição, suporte e fator essencial para a existência do homem sobre a terra". 14

A aproximação metodológica não dogmática, dada pela doutrina espanhola, de somente reconhecer tutela aos recursos naturais mais tradicionais o ar e a água justifica-se por serem o suporte da própria existência do homem e dos seres vivos e, quando inadequadamente manejados, veicularem toda uma série de transtornos dos processos ambientais: "Esta comprensión limitada explica por qué cuando se quiere expandir el contenido se adiciona al amibente el término: 'recursos naturales`. Otras veces se utiliza con el mismo objeto una expresión mas genérica: 'protección de la naturaleza', aunque quizás com ello se pretende matizar a ampliación del campo considerado, incluyendo aspectos como los de la defensa de la flora, fauna y suelo, creación de parques naturales y reservas especiales, etc.". 15

As referências metodológicas descobrem o conteúdo do meio ambiente, que aparece na norma juridica do artigo $225,{ }^{16}$ dado pelo legislador

aspectos estéticos de la geografia humana. los monumentos y cuidades artisticas. No quiere decirse con esto yue tal problemática se atrivial o carente de interés. sino yue no es fácil encontrar critérios e princípios unificadores de toda esta variada materia. como no sea su imprecisa reconducción a los postulados del equilibrio general de la biosfera. pero aun así. y aun admitiendo que ef etivamente a la postre todo este tipo de estrategias tienen un denominador comum de caráter macroambiental. sólo un enfoque ambiental mas circunscrito como el que ayui se propugna puede legitmar el algut in ar el conjunto jurídico que denominamos derecho ambiental".

1.4 Ramón Martin Mateo. Tratado..., op. cit. p. 86: "(...) Puede pensarse também yue entre tales element os cabría incluir el suelo (...). peero creemos yuÿ la gestión del suelo o bien se reconduce a la ordenación global del território y a lucha contra la erosión con transcendencia más ampla yue la propia gestión ambiental. o a la postre se conecta con los ciclos del agua y del aire. bien encuanto a las sustancias depositadas en el suelo y que en ayuéllos se transportam. bien en cuanto a eventuales alt eraciones de estos ciclos al pertubases las condiciones meteorologicas. por obra. por ejemplo de la desforestación".

15 Idem.

16 Artigo 225. "Todos têm direito ao meio ambiente ecologicamente equilibrado. bem de uso do povo e essencial à sadia qualidade de vida. impondo-se ao Poder Público è à coletividade o dever de defendê-lo e preservá-lo para as presentes e futuras gerações. Parágrafo $1^{\circ}$ - Para assegurar a efetividade desse direito. incumbe an Poder Público: I. - preservar e restaurar os processos ecológicos essenciais e prover o manejo ecológico das espécies e ecossistemas: II. - preservar a diversidade e a integridade do patrimônio

R. Fac. Dircito. Curitiba. a.27.n.27. 1992/93. p.81-91 


\section{brasileiro na atual Constituição Federal de 1988 que compreende a proteção da fauna, da flora, dos recursos naturais. ${ }^{17}$}

genético do País e fiscalizar as entidades dedicadas à pesquisa e manipulação de material genético; III. - definir, em todas as unidades da Federação, espaços territoriais e seus componentes a serem especialmente protegidos, sendo a alteração e a supressão permitidas somente através de lei, vedada qualquer utilização que comprometa a integridade dos atributos que justifiquem sua proteção; IV. - exigir, na forma da lei, para instalação de obra ou atividade potencialmente causadora de significativa degradação do meio ambiente, estudo prévio de impacto ambiental, a que se dará publicidade; V. controlar a produção, a comercialização e o emprego de técnicas, métodos e substâncias que comportem risco para a vida, a qualidade de vida e o meio ambiente; VI. - promover a educação ambiental em todos os níveis de ensino e a conscientização pública para a preservação do meio ambiente; VII. - proteger a fauna e a flora, vedadas, na forma da lei, as práticas que coloquem em risco sua função ecológica, provoquem a extinção de espécies ou submetam os animais à crueldade. Parágrafo $2^{\circ}$. - Aquele que explorar recursos minerais fica obrigado a recuperar o meio ambiente degradado, de acordo com soluçào técnica exigida pelo órgão público competente, na forma da lei. Parágrafo $3^{\circ}$ As condutas e atividades consideradas lesivas ao meio ambiente sujeitarão os infratores, pessoas físicas ou jurídicas, a sanções penais e administrativas, independentemente da obrigação de reparar os danos causados. Parágrafo $4^{\circ}$. - A Floresta Amazônica brasileira, a Mata Atlântica, a Serra do Mar, o Pantanal Mato-Grossense e a Zona Costeira são patrimônio nacional, e sua utilização far-se-á, na forma da lei, dentro de condições que assegurem a preservação do meio ambiente, inclusive quanto ao uso dos recursos naturais. Parágrafo $5^{\text {o. }}$ - São indisponíveis as terras devolutas ou arrecadadas pelos Estados, por ações discriminatórias, necessárias à proteção dos ecossistemas naturais. Parágrafo $6^{\circ}$. - As usinas que operam com reator nuclear deverão ter sua localização definida em lei federal, sem o que não poderão ser instaladas.

17 A doutrina comparada utiliza-se da expressão recursos naturais e parece que há um consenso em citar: o solo, o subsolo, a água, o ar, a flora e a fauna. A Lei Nacional brasileira de 1981 que dispõe sobre a Política do meio ambiente, no inciso V do artigo $3^{\circ}$ o define: recursos ambientais: a atmosfera, as águas interiores, superficiais e subterrâneas, os estuários, o mar territorial, o solo, o subsolo e os elementos da biosfera". Esta por sua vez a biosfera é constituída pela camada de solo, de água que circundam o globo terrestre onde reina as condições necessárias à vida. Ela compreende os elementos minerais ou abióticos (o solo, a água, o ar) e a energia transportada pelo raio solar (Alexandre Kiss, L'Ecologie et la Loi, Paris, Editions Hormattan, 1989. p. 15-26). Na verdade, a terminologia utilizada pelo legislador brasileiro para substantivar a matéria direito ambiental, não dá suporte à uma possível interrelação jurídica entre noção (a idéia do objeto de estudo), definição (delimitação conceitual: em que consiste sua essência; indicação dos fins ou limites conceituais de um objeto dado com relação aos demais) e sua conceituação (o pensamento sobre a aplicação do objeto de estudo no espaço: como este o é concebido no Direito). Sua definiçào é concebida em sentido extremamente geral e bastante vago. O legislador deixa entrever uma clara falta de familiaridade com tais terminologia provindas de outras ciências, cujo ele é obrigado a realizar o processo de qualif icação jurídica, aos as adequar no quadro legislativo e frente aos tribunais. Segundo alguns doutrinadores brasileiros (José Frederico Marés de Souza. Espaços ambientais 
Mmmm Por isso, muitas vezes, não há definiçõeos completas, assim como não existe ainda, no âmbito legal, uma nomenclatura precisa e definida, que tenha homogeneidade de conceitos". (a proteção da àgua, do ar e do solo), a proteção da natureza denominadas Unidades de Conservação Flo-resta Amazônica, da Zona Costeira, assim como o Monumento Natural Serra do Mar. A observação de que a proteção da natureza, que é a origem do Capítulo sobre o Meio Ambiente e suas variações normativas vai ultrapassar a concepção de proteção da natureza colocada sob tutela no Capítulo da Cultura, nem sempre tomada dentro de uma concepção eletista de tutela de preservação ${ }^{18}$ aos sítios preliminarmente protegidos pelo Artigo 216. Insere-se ainda, ao lado das regras e das técnicas de proteção (métodos de proteção implícitos nos incisos I. II. III e V), o domínio concernente à proteção das instalações de obras ou atividades potencialmente causadoras de significativa degradação do meio ambiente, realizadas pelo Poder Público (Inciso V). Assim, a concepção de meio ambiente que provém do Capítulo sobre Meio Ambiente na Constituição Federal Brasileira de 1988 é, pois, de caráter amplo ao aceite da doutrina brasileira mais moderna, que. diante do conceito de ambiente apresentado por Giannini, ${ }^{19}$ busca uma aproximação unitária do termo ambiente, ${ }^{20}$ que é definido deste modo: "a

Protegidos e Unidades de Conservação. Curitiha. I ditora Iniversitiria Champagnan 1993. p. 13): "A legislação especifica que regula o conjunto dos espaços protegidos no Brasil e que serve de fundamento para a criaçăo das unidades. e que somados an procedimento de constituição e regulamentação formam a principal parte do bircito Ambiental. está ainda em formação.

"O que é preservação no seu sentido técnico-juridico?" F.C. in: Inccionnairc d'U rbanisme, Paris. Press Universitaire de France. 1988. p. 534 responde: "Pratiquement synonyme de sauvegarde. Action globale consistant a assurer la protection du patrimoine architectural et naturel contre l'action destructrice des hommes. par une legislation appropriée. et sa conservation dans le temps a laide des lechniques dentretien. de consolidation et de restauration pourant. elles aussi. ressont ir a une condification legale".

19 A questão tem despertado a atenção de (iiannini. que. ao tentar delimitar com maior nitidez possivel o sentido do termo amhiente. opõe às legislações de conteúdo juridico pontual e setorial, o conceito: " $O$ ambiente enquanto conservação da paisagem incluindo, tanto as belezas naturais como os centros histiricos: " ambiente enquanto nommativa relacionada com a defesa do solo, do ar e da agua: e o ambiente enquanto objeto da disciplina urbanística. (Ramón Martin Mateo. Tratado..., op. cit., p. 83).

20. José Afonso da Silva. Iireito Ambiental ('onstitucional. São Paulo. Malheiros Fditora. 1994. p. 2: "() ambiente integra-se. realmente. de um conjunto de elementos naturais e culturais. cuja interação constitui e condiciona o meio em que se vive. 1)aí porque a expressão meio ambiente se man if esta mais rica de sentido (como conexão de valores do que a simples palavra ambiente). Esta exprime o conjunto de elementos: aquela expressa o resultado da interação desses elementos".

R. Fac. Direito. Curitiba. a.27. n.27. 1992/93. p.81-91 
interação de conjunto de elementos naturais, artificiais e culturais que propiciem o desenvolvimento equilibrado da vida em todas as suas formas". ${ }^{21}$

Que elementos serão estes objetos de uma proteção jurídica específica? O conteúdo dado por José Afonso da Silva à sua definição de meio ambiente há de ser o mais estendido possível, e tomado em três aspectos diferenciadores: "O meio ambiente natural ou físico (constituído pelo solo, a água, o ar atmosférico, a flora, enfim, pela interação dos seres vivos e seu meio, onde se dá a correlação recíproca entre as espécies e as relações destas com o ambiente físico que ocupam), o meio ambiente artificial (constituído pelo espaço urbano construído, consusbstanciado no conjunto de edificações (espaço urbano fechado), e dos equipamentos públicos (ruas, praças, áreas verdes, espaços livres em geral: espaço urbano aberto) e o meio ambiente cultural (integrado pelo patrimônio histórico, artístico, arqueológico, paisagístico, turístico, que, embora artificial, em regra, como obra do homem, difere do anterior (que também é cultural) pelo sentido de valor especial que adquiriu ou de que se impregnou)". ${ }^{22}$

Aspectos que os diferencia quanto ao regime jurídico de proteção e os delimita frente a outras classes de bens do ponto de vista dos valores essenciais que tais bens possam representar para as "presentes e futuras gerações".

\section{Conclusão}

Sem dúvida, esta matéria Direito Ambiental é considerada de difícil desenvolvimento. A complexidade se deve à natureza peculiar do objeto central de seu estudo de transcendência homogênia tradicional. A imprecisão terminológicas que afeta a legislação brasileira é a mesma na legislação comparada. Depara-se com um problema jurídico, que para J. de Lanversin, é a regra nas ciências em curso de desenvolvimento. Entretanto, no caso do meio ambiente, este reveste um caráter de gravidade bem maior, porque o meio ambiente é ele mesmo o objeto da ciência a subsistência da disciplina que é a sede da indeterminação fundamental. ${ }^{23}$

21 José Afonso da Silva, Direito... op. cit., p. 2.

22 José Afonso da Silva, Direito... op. cit., p. 3.

23 Michel Despax, "Aspects Juridiques de la protection de l'Environnement", Colloque de Tunis: La Protection Juridique de L'Environnement, Colloque de Tunis, Faculté des

I.AMARQIH:. .ean. Iroit de la protection de la nature e't de l'emvironnement. Paris: I. G 1). 1. 1973

KISS. Alexandre. I.'Ecologie et la Loi., l'aris: liditions l'Hormattan. 1989. 391 p.

MATlE(). Ramon Martin. Tratado de loerecho Ambiental. v. I. Madrid: Editora Trivium. 1991 $501 \mathrm{p}$

RI:IS. João Ferreira. Contributos para uma Teoria do Direito do Ambiente. I isboa: Secretaria do Estado do Ambiente e dos Recursos Naturais. 1987.67p 


\section{Referências Bibliográficas}

CRETHIIA JUNIOR. José ét al. Dicionário Latino-P'ortuguès. 3. edição. São Paulo: Companhia Editora Nacional. 1993.

DESPAX. Michel. "Aspects huridiques de la protection de lenvironnement." Colloque de Tunis: L.A PROTE(TION JRII)IOUE DE L'ENTIRONNEMENT. Tunis: Faculté des Sciences Juridiques. Politiques et Sociales de Tunis. 1989.

FARIAS. Bemadete Ferreira. La legislation de Protection du Patrimoine (ultural. Strasbourg. Faculté de Sciences Politiques e de Gestion. Université Robert Schumdr III. 1991. $319 \mathrm{p}$.

HIIENTES. Femando Bodelon. ("alidade de lïda. Medio Ambiente y ()rdenacion del Territória. ․ I. Textos Intemacionais. Madrid: CPoTMA/CIFCA. 1982. $857 \mathrm{p}$

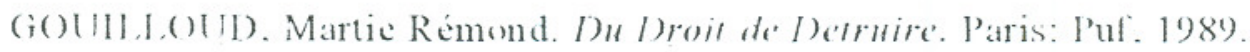

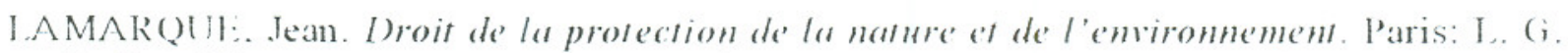
1). 1. 1973 .

KISS. Alexandre. I' Ecologie et la Loi., l'aris: liditions l'Hormattan. 1989. $391 \mathrm{p}$.

MATYO(). Ramón Martin. Tratado de Lerecho A mbiental. v. I. Madrid: Fditora Trivium. 1991. $501 \mathrm{p}$.

REIS. João Ferreira. Cont ributos para uma Teoria do Direito do Ambiente. I isboa: Secret aria do Fstado do Ambiente e dos Recursos Naturais. $1987.67 \mathrm{p}$.

\section{Dicionários}

Diceionnaire d't rhanisme. Paris: Presses (Jniversitária de lramça. 1988. $723 \mathrm{p}$.

Novol licionario Aurélio da lingua Portuguesa. Rio de Janciro: . I. M. M. Iditores I ada sd.

Constituição da Republica lederativa do Brasil. São Paulo: E⿰ditora dos Tribunais. 1988. $204 \mathrm{p}$.

Sciences Juridiques. Politiques et Sociales de Tunis. 1989. p. 94.

R. Fac. I)ireito. Curitiba. a.27. n.27. 1992/93. p.81-91 